\title{
ESTIMATION OF THE NUMBER OF NEURONS IN THE HIPPOCAMPUS OF RATS WITH PENICILLIN INDUCED EPILEPSY
}

\author{
ILGAZ AKDOGAN $^{1}$, NEDIM UNAL ${ }^{2}$ AND ESAT ADIGUZEL ${ }^{1}$ \\ ${ }^{1}$ Department of Anatomy, Medical School of Pamukkale University, Denizli, Turkey, ${ }^{2}$ Department of Anatomy, \\ Medical School of Osmangazi University, Eskisehir, Turkey \\ e-mail: ilgazakdogan@yahoo.com \\ (Accepted. February 17, 2002)
}

\begin{abstract}
Epilepsy is a neurological disease arising from strong and uncontrollable electrical firings of a group of neurons in the central nervous system. Experimental epileptic models have been developed to assess the physiopathology of epileptic seizures. This study was undertaken to estimate the number of neurons in the rat hippocampus with penicillin induced epilepsy, using a stereological method, 'the optical fractionator". In the experimental group, $500 \mathrm{IU}$ penicillin-G was injected intra-cortically, and in the control group, the same volume of saline was administered. A week later, the animals were decapitated and their brains were removed by craniatomy. Frozen brains were cut with a thickness of $150 \mu \mathrm{m}$ in a cryostat. Sections were collected by systematic random sampling and stained with hematoxylen-eosin. Microscopic images of pyramidal cell layers from hippocampus CA1, CA2 and CA3 subfields were then transferred to a monitor, using a 100x objective $($ N.A. = 1.25). Using the optical disector method, the neurons were counted in the frames and determined with a fractionator sampling scheme. The total pyramidal neuron number was then estimated using the optical fractionator method. The total pyramidal neuron number was found to be statistically lower in the experimental group (mean $=142,888 \pm 11,745)$ than in the control group (mean $=177,953 \pm 10,907)$ $(\mathrm{p}<0.05)$. The results suggest that a decrease in the hippocampal neuronal number in a penicillin model of epilepsy can be determined objectively and efficiently using the optical fractionator method.
\end{abstract}

Keywords: experimental epilepsy, hippocampus, optical fractionator, rat, total neuron number.

\section{INTRODUCTION}

Epilepsy is a neurological disease arising from abnormal and uncontrollable electrical firings of a group of neurons appearing in the central nervous system (Fletcher, 1987; Lindsay et al., 1997). Experimental epilepsy models were developed to assess the physiopathology of epileptic seizures (Biziere and Chambon, 1987). Animal models with epilepsy can be classified as: 1) experimental seizures induced by chemical convulsants or by electrical stimulation, 2) reflex epilepsies, 3) idiopathic epilepsies (Biziere and Chambon, 1987).

Chemical convulsants are widely used as simple and rapid seizures (Biziere and Chambon, 1987). The common antibiotic, penicillin, is a chemical convulsant (Biziere and Chambon, 1987; Fisher, 1989). If penicillin is injected into the brain intra-cortically, it develops epileptic seizures (Sagratella et al., 1985). No previous studies of the changes in the neuronal number of the rat hippocampus in the penicillin model of experimental epilepsy have been made. Other experimental models have shown a decrease in the neuronal number in the hippocampus, but none of them has used a stereological method. The aim of this study was to estimate the number of neurons in the hippocampus of penicillin induced epileptic rats using the optical fractionator. The optical fractionator is an unbiased stereological method for counting neurons (West, 1993). It combines a three-dimensional probe for counting neuronal nuclei, i.e. the optical disector, with a systematic random sampling scheme, the fractionator as (Gundersen, 1986; Gundersen et al., 1988; West et al., 1991, 1996). The optical disector produces unbiased estimates of neuron number, i.e., estimates free of assumptions about neuron size and shape, unaffected by lost caps and overprojection. The fractionator involves systematic sampling of a known fraction of a structural component (West et al., 1991).

\section{MATERIALS AND METHODS}

Twelve Sprague-Dawley female rats aged 16-20 weeks were used in this study $(\mathrm{n}=6$ experimental group, $\mathrm{n}=6$ control group). The animals were fully anesthetized with a combination of Xylazine (10 $\mathrm{mg} / \mathrm{kg}$ ) and Ketamine $(90 \mathrm{mg} / \mathrm{kg})$ intra-peritoneally. 
In the experimental group, 500 IU $(0.1 \mathrm{cc}$.) penicillin-G was injected intra-cortically $(2 \mathrm{~mm}$. posterior and $2 \mathrm{~mm}$ lateral from the bregma, and 2 $\mathrm{mm}$ into the right cortex). The seizures happened 2-3 minutes after injection, and the epileptiform activity was recorded by EEG. In the control group, the same volume of saline $(0.1 \mathrm{cc} ., 0.9 \% \mathrm{NaCl})$ was administered and no changes of electrical activity in EEG was observed.

A week later, all animals were decapitated, their brains were removed by craniotomy and frozen in a cryostat (Leica CM3050) at $-50^{\circ} \mathrm{C}$. Frozen brains were cut in the horizontal plane with a thickness of $150 \mu \mathrm{m}$ by the cryostat at $-15^{\circ} \mathrm{C}$. Sections were collected via systematic random sampling and stained with hematoxylen-eosin.

Microscopic images obtained from pyramidal cell layers in CA1, CA2, CA3 subdivisions of the hippocampus using $100 \times$ oil objective $($ N.A. $=1.25$ ) with a microscop (Nicon Eclipe E 600) were transferred to a monitor (Sony Trinitron Color Video Monitor PVM - 14N1MDE) using a video camera (Hitachi OSP Color Video CameraVK - C22OE).

\section{NEURONAL COUNTS AND OPTICAL FRACTIONATOR}

\section{Sections}

The sampled sections were chosen according to the systematic random sampling scheme. The first section in the series to be analyzed was chosen randomly from the first 2-4 sections. This section and every $2^{\text {th }}-4^{\text {th }}$ section thereafter was stained for use in the analysis. The section sampling fraction, ssf, is thus $1 / 2-1 / 4$.

\section{Sectional Area}

In each of the sections to be sampled, neurons were counted with the optical disector at regularly predetermined $\mathrm{x}, \mathrm{y}$ axis within the CA1, CA2 and CA3 subdivisions. Step " $\mathrm{x}$ " was predetermined to $300 \mu \mathrm{m}$ and step "y" to $300 \mu \mathrm{m}$. Microscopic images obtained from pyramidal cell layers in CA1, CA2 and CA3 subdivisions of the hippocampus using 100xoil objective were transferred to a monitor. An unbiased counting frame (Gundersen's unbiased counting frame) (West et al., 1991) was then super-imposed on the monitor image of the section. The area of the counting frame of the disector, a (frame), was known $\left(25 \mu \mathrm{m} \times 25 \mu \mathrm{m}=625 \mu \mathrm{m}^{2}\right.$ or $20 \mu \mathrm{m} \times 20 \mu \mathrm{m}=400$ $\mu \mathrm{m}^{2}$ ) relative to the area associated with each $\mathrm{x}, \mathrm{y}$ movement, a (x, y step). Thus, the areal sampling fraction is (asf) $=\mathrm{a}($ frame) $/ \mathrm{a}(\mathrm{x}, \mathrm{y}$ step) .

\section{Section Thickness}

At each step of the sampled pyramidal cell layer where the neuronal nuclei were observed under the frame, the plane of focus was moved $10 \mu \mathrm{m}$ from the surface into the section. The counting frame was then focused through $30 \mu \mathrm{m}$ of the thickness of the section and the number of neuronal nuclei was counted with unbiased counting rules $\left(\mathrm{Q}^{-}\right)$. With the optical disector, it is only necessary to determine the first recognizable profile of the nucleus to come into focus within the counting frame. The height of the disector was $30 \mu \mathrm{m}$ for this study $(\mathrm{h}=30 \mu \mathrm{m})$.

At each step in the sampled pyramidal cell layer, the distance between the top and the bottom surfaces i.e., the positions at which the neuronal nuclei first came into focus from above and below the section, was determined (Korkmaz and Tümkaya, 1997), indicating that shrinkage is homogeneous within each studied section. The mean thickness of each section was calculated. The fraction of the sampled section thickness is referred to as the thickness sampling fraction (tsf) $=\mathrm{h}$ (the height of the disector)/t (the mean thickness of the section).

Neurons were directly counted in the known fraction of CA1, CA2 and CA3 subdivisions of the hippocampus. The number of neurons in the CA1, CA2 and CA3 subdivisions (N) was estimated as:

$$
\mathbf{N}=\mathrm{Q}^{-} \mathrm{x}(1 / \mathrm{ssf}) \times(1 / \mathrm{asf}) \times(1 / \mathrm{tsf}) \text {, }
$$

Q: The total number of neurons counted in the disectors on the sampled sections.

\section{RESULTS}

Neurons were counted by applying the optical disector method in the frames determined with the fractionator sampling scheme. We observed that the pyramidal neuron number in hippocampus CA1, CA2 and CA3 subdivisions was significantly lower in the experimental group (mean \pm standart error $=142,888$ $\pm 11,745$ ) (Table 1) than in the control group (mean \pm standart error $=177,953 \pm 10,907)$ (Table 2), (Mann Whitney U test, $\mathrm{p}<0.05$ ) (Fig. 1). Our results for the control group differ from those obtained by West et al. (1991) for normal Wistar rats using the same stereological strategy. This may be explained by different animal species and age of the rats, different tissue handling protocols and probably different delineation of hippocampal regions between this study and the study by West et al. 


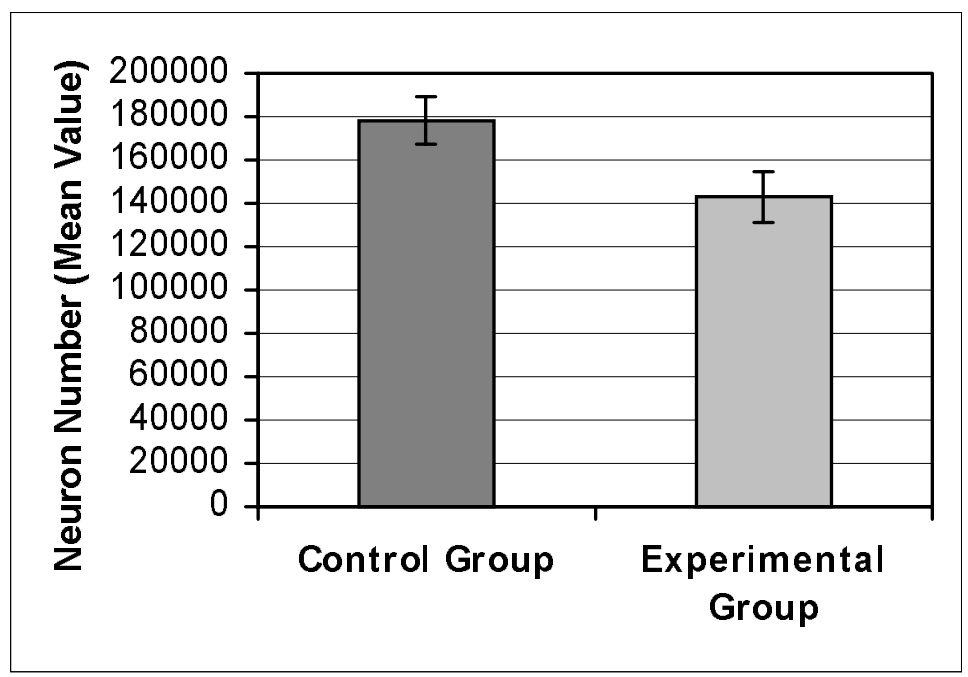

Fig. 1. Total pyramidal neuron number of CA1, CA2, CA3 subdivisions of the left hippocampus in control and experimental group rats. For both groups $n=6 ; \%$ difference $=\% 19.71 ; p<0.05$.

Table 1. Total number of neurons of CA1, CA2 and CA3 subdivisions in the left hippocampus in the experimental group (penicillin induced epileptic rats) and parameters estimating total number of neurons.

\begin{tabular}{l|c|c|c|c|c|c}
\hline & Experimental & Experimental & Experimental & Experimental & Experimental & Experimental \\
& 1 & 2 & 3 & 4 & 5 & 6 \\
\hline $\mathrm{Q}^{-}$ & 128 & 140 & 125 & 117 & 111 & 132 \\
$1 / \mathrm{ssf}$ & 4 & 2 & 4 & 4 & 4 & 3 \\
$1 / \mathrm{asf}$ & 144 & 225 & 144 & 144 & 144 & 144 \\
$1 / \mathrm{tsf}$ & 1.78 & 2.07 & 2.14 & 2.34 & 2.30 & 2.40 \\
$\mathrm{t}(\mu \mathrm{m})$ & 53.60 & 62.20 & 64.40 & 70.40 & 69.00 & 72.00 \\
$\mathrm{~h}(\mu \mathrm{m})$ & 30 & 30 & 30 & 30 & 30 & 30 \\
$\mathrm{a}(\operatorname{area}$ of the unbiased & 625 & 400 & 625 & 625 & 625 & 625 \\
counting frame $\left(\mu \mathrm{m}^{2}\right)$ & & & & & & \\
\hline $\mathrm{N}($ The total number of & 131,235 & 130,410 & 154,080 & 157,697 & 147,052 & 136,857 \\
neurons) & & & & & & \\
\hline
\end{tabular}

Table 2. Total number of neurons of CA1, CA2 and CA3 subdivisions in the left hippocampus in the control group rats and parameters estimating total number of neurons.

\begin{tabular}{l|c|c|c|c|c|c}
\hline & Control & Control & Control & Control & Control & Control \\
& 1 & 2 & 3 & 4 & 5 & 6 \\
\hline $\mathrm{Q}^{-}$ & 179 & 144 & 151 & 147 & 138 & 134 \\
$1 / \mathrm{ssf}$ & 2 & 4 & 4 & 4 & 4 & 4 \\
$1 / \mathrm{asf}$ & 225 & 144 & 144 & 144 & 144 & 144 \\
$1 / \mathrm{tsf}$ & 2.05 & 2.01 & 2.07 & 2.30 & 2.29 & 2.32 \\
$\mathrm{t}(\mu \mathrm{m})$ & 61.78 & 60.40 & 62.20 & 69.00 & 68.80 & 69.60 \\
$\mathrm{~h}(\mu \mathrm{m})$ & 30 & 30 & 30 & 30 & 30 & 30 \\
$\mathrm{a}$ area of the unbiased & 400 & 625 & 625 & 625 & 625 & 625 \\
counting frame $\left(\mu \mathrm{m}^{2}\right)$ & & & & & & \\
\hline $\mathrm{N}($ The total number of & 165,127 & 166,717 & 180,040 & 194,745 & 182,027 & 179,066 \\
neurons) & & & & & & \\
\hline
\end{tabular}




\section{DISCUSSION}

Using the optical fractionator design based method, we showed that the total number of neurons in the CA1, CA2 and CA3 pyramidal cell layers of the hippocampus of penicillin induced epileptic rats is statistically lower than in the control group. This tendency has been acknowledged previously (Dam, 1982). However, because the numerical cell densities reported by Dam (1982) are likely to be 'biased' by tissue shrinkage or swelling (West et al., 1991; Oorschot, 1994; Howard and Reed, 1998), we believe that our results are more reliable. Furthermore, our design based method does not require such correction factors (Abercrombie correction factor) as it is the case for the model based method reported by Boss et al (1987).

Based on the sole knowledge of the sampled fraction of the CA1, CA2 and CA3 pyramidal layers of the hippocampus, the optical fractionator allowed us herein to estimate the total number $(\mathrm{N})$ of neurons. This design based stereological strategy avoids the bias that may be introduced in approaches where the calculation of $\mathrm{N}$ relies on the estimation of a numerical cell density $(\mathrm{Nv})$ and of a reference volume (Vref) as expressed by the formula given in Coggeshall and Lekan (1996) and Gundersen et al. (1988): N = Nv X Vref. Indeed, Vref is nearly always estimated on un-embedded tissue section which may not be shrunken, whereas $\mathrm{Nv}$ is evaluated on embedded histological sections which typically are shrunken. In such a case, knowing how difficult it is to correct for shrinkage, the calculation of $\mathrm{N}$ would be biased.

This leads us to conclude, that the optical fractionator shall be used to estimate objectively and efficiently the neuronal number of the central nervous system.

\section{ACKNOWLEDGEMENTS}

Authors thank to Atilla OGUZHANOGLU, Turker SAHINER (Department of Neurology, Medical School of Pamukkale University) and Ender DUZCAN (Department of Pathology, Medical School of Pamukkale University, TURKEY).

\section{REFERENCES}

Biziere K, Chambon JP (1987). Modeles Animaux D'epilepsie et Crises Experimentales. Rev Neurol (Paris) 143(5):329-40.

Boss BD, Turlejski K, Stanfield BB, Cowan WM (1987). On the numbers of neurons in fields CA1 and CA3 of the hippocampus of Sprague-Dawley and Wistar rats. Brain Research 406:280-7.

Coggeshall RE, Lekan HA (1996). Methods for determining numbers of cells and synapses: A case for more uniform standards of review. The Journal of Comparative Neurology 364:6-15.

Dam AM (1982). Hippocampal neuron loss in epilepsy and after experimental seizures. Acta Neurol Scandinav 66:601-42.

Fisher RS (1989). Animal Models of the Epilepsies. Brain Research Rev 14:245-78.

Fletcher AJ (1987). In: Berkow R, Ed. The Merck Manual of Diagnosis and Therapy. Fifteenth Edition. Merck Sharp and Dohme Research Laboratories, pp. 1366.

Gundersen HJG (1986). Stereology of arbitrary particles, A review of unbiased number size estimators and the presentation of some new ones, in memory of William R. Thompson. Journal of Microscopy 143:3-45.

Gundersen HJG, Bagger P, Bendtsen TF, Evans SM, Korbo L, Marcussen N, Moller A, Nielsen K, Nyengaard JR, Pakkenberg B, Sorensen FB, Vesterby A, West MJ (1988). The new stereological tools: disector, fractionator, nucleator and point sampled intercepts and their use in pathological research and diagnosis, review article. APMIS 96:857-81.

Howard CV, Reed MG (1998). Unbiased Stereology Three-Dimensional Measurement in Microscopy. BIOS Scientific Publishers, 94-5.

Korkmaz A, Tünkaya L (1997). Estimation of the section thickness and optical disector height with a simple calibration method. Journal of Microscopy 187(2): 104-9.

Lindsay KW, Bone I, Callender R (1997). Neurology and Neurosurgery Illustrated. $3^{\text {th }}$ edition. Churchill Livingstone, pp.88.

Oorschot DE (1994). Are you using neuronal densities, synaptic densities or neurochemical densities as your definitive data? There is a better way to go. Progress in Neurobiology 44:223-47.

Sagratella S, Niglio T, Carolis AS (1985). An investigation on the mechanism of anticonvulsant action of ketamine and phencyclidine on convulsions due to cortical application of penicillin in rabbits. Pharmacological Research Comm 17(8):773-86.

West MJ, Slomianka L, Gundersen HJG (1991). Unbiased stereological estimation of the total number of neurons in the subdivisions of the rat hippocampus using the optical fractionator. The Anatomical Record 231:4827.

West MJ (1993). New stereological methods for counting neurons. Neurobiology of Aging 14:275-85.

West MJ, Ostergaard K, Andreassen OA, Finsen B (1996). Estimation of the number of somatostatin neurons in the striatum: An in situ hybridization study using the optical fractionator method. The Journal of Comparative Neurology 370:11-22. 